\title{
Imageamento elétrico no estudo de aterro de resíduos domésticos de pequeno porte
}

\author{
Vagner Roberto Elis ${ }^{1}$, Andrea Teixeira Ustra ${ }^{1}$, Cristiano Kenji Iwai ${ }^{2}$, Vitor Lucas Sobottka Cavenaghi ${ }^{1}$ \\ ${ }^{1}$ Departamento de Geofísica. Instituto de Astronomia, Geofísica e Ciências Atmosféricas USP \\ ${ }^{2}$ CETESB - Companhia Ambiental do Estado de São Paulo
}

Copyright 2016, SBGf - Sociedade Brasileira de Geofísica

Este texto foi preparado para a apresentação no VII Simpósio Brasileiro de Geofísica, Ouro Preto, 25 a 27 de outubro de 2016. Seu conteúdo foi revisado pelo Comitê Técnico do VII SimBGf, mas não necessariamente representa a opinião da SBGf ou de seus associados. É proibida a reprodução total ou parcial deste material para de seus associados. E proibida a reprodução total ou
propósitos comerciais sem prévia autorização da SBGf.

\section{Resumo}

No Brasil, aterros sanitários são considerados locais adequados para disposição de resíduos domésticos, de forma a minimizar impactos ambientais. No entanto, em pequenas cidades que produzem menos de 10 toneladas de resíduos domésticos por dia, é comum os resíduos serem depositados diretamente no solo, sem qualquer critério técnico. Na busca de melhorar esta situação, a agência ambiental propôs a disposição dos resíduos em aterros tipo vala para os municípios de pequeno porte. Sua implementação simples tem sido altamente contestada, tornando importante a investigação ambiental deste tipo de aterro para avaliar seus impactos no meio ambiente. Este artigo apresenta os resultados de ensaios geoelétricos em um aterro sanitário em vala como ferramenta de avaliação de seu impacto ambiental.

\section{Introdução}

Os impactos ambientais causados pela intervenção do homem ao meio ambiente consistem atualmente uma das grandes preocupações mundiais. A crescente concentração populacional em áreas urbanas e 0 consequente aumento da produção de resíduos domésticos vêm gerando muitos problemas relacionados à contaminação de solos e águas subterrâneas devido à deposição inadequada desses resíduos.

No Brasil, os aterros sanitários são considerados os locais ideais para a deposição dos resíduos sólidos e quando projetados apropriadamente reduzem o perigo para a saúde pública e para a segurança. $O$ aterro sanitário tem sido adotado como a solução de destinação final dos resíduos sólidos urbanos para cidades de grande e médio porte, que teoricamente têm capacidade técnica e econômica para implementar e manter em funcionamento adequado este tipo de depósito (Castilhos, 2003).

Porém, o destino apropriado dos resíduos gerados em pequenas cidades, que produzem menos de 10 toneladas de resíduos por dia, ainda é um desafio para o governo. A falta de conhecimento técnico e recursos financeiros para a disposição adequada dos resíduos geralmente resulta em numerosos depósitos a céu aberto.

Com o objetivo de melhorar esse quadro, a Companhia de Saneamento Ambiental do Estado de São Paulo
(CETESB) propôs uma alternativa de baixo custo financeiro e ambiental para ser implementada em cidades com menos de 25.000 habitantes. A solução técnica proposta pela CETESB é a disposição em aterros em valas, que consiste no preenchimento de valas escavadas com dimensões apropriadas, onde os resíduos são depositados sem compactação e sua cobertura com solo é realizada manualmente. É aconselhável que tais aterros sejam construídos em solos argilosos e siltosos, homogêneos e com permeabilidade ao redor de $10^{-7} \mathrm{~cm} / \mathrm{s}$.

Atualmente existe um grande número de aterros em valas no Estado de São Paulo e, devido a sua implementação simplificada altamente contestada, tornase importante avaliar por meio de técnicas de investigação ambiental os possíveis impactos ao meio ambiente que este tipo de disposição de resíduos pode acarretar. A proposta desse trabalho é estudar por meio de ensaios geoelétricos uma área de aterro em valas como forma de avaliar suas implicações ambientais, principalmente nas relações entre características geológicas (solos e águas subterrâneas), migração de chorume e atenuação da contaminação.

\section{Área de estudos}

O aterro em valas avaliado está localizado na cidade de Luís Antônio, a cerca de 300 quilômetros de São Paulo. A cidade se encontra na área de afloramento do Grupo São Bento, o qual é composto pelas formações Serra Geral e Botucatu. O aterro está instalado sobre solo argiloso dos basaltos da Formação Serra Geral.

O aterro em valas de Luís Antônio está ativo desde 1999 e operando com valas de cerca de 70 metros de comprimento, 8 metros de largura e 6 metros de profundidade.

No caso desse tipo de aterro, devido à técnica construtiva e às dimensões reduzidas das valas, não são utilizados solos compactados como base impermeável. Dessa forma, esse tipo de aterro requer solos com permeabilidade favorável e nível d'água no mínimo 3 metros abaixo da base da vala. $\mathrm{Na}$ área do aterro em questão o solo apresenta permeabilidade de $1 \times 10^{-5} \mathrm{~cm} / \mathrm{s}$ e profundidade do nível d'água de pelo menos 12 metros (Iwai, 2012).

\section{Metodologia}

Como o objetivo desse estudo foi avaliar se existe contaminação do solo e das águas subterrâneas por meio de ensaios de resistividade, a pesquisa foi realizada primeiro com modelagem direta de dados - para entender 
a possível resposta geoelétrica desse tipo de depósito - e depois foram realizados ensaios no depósito. Tanto para a modelagem como para os ensaios de campo, foi utilizado o arranjo dipolo-dipolo com espaçamento de 5 metros e 10 níveis de investigação.

No estudo com dados sintéticos, primeiramente foram criados modelos 2D com o software de modelagem direta RESIXIP2Di (INTERPEX, 1997) e gerados arquivos de dados de resposta geoelétrica para esses modelos. Em seguida os dados calculados por esses modelos foram submetidos a inversão com o software RES2Dinv (LOKE, 2007), que resultaram em seções de resistividade esperadas para duas situações que podem ocorrer na área de estudo: a) Vala preenchida com resíduos e com nível de chorume, sem infiltração na base e b) Vala preenchida com resíduos e com nível de chorume, com infiltração de chorume no solo. Os valores de resistividade usados nos modelos são os esperados para esses tipos de situações no território brasileiro.

Em seguida foram realizados ensaios na área de estudo, em locais com resíduos (2 perfis na extensão das valas e um perfil atravessando várias valas) e perfis a montante e jusante da área, para verificar as respostas em locais sem resíduos e avaliar se existe fluxo lateral de contaminantes (Figura 1)

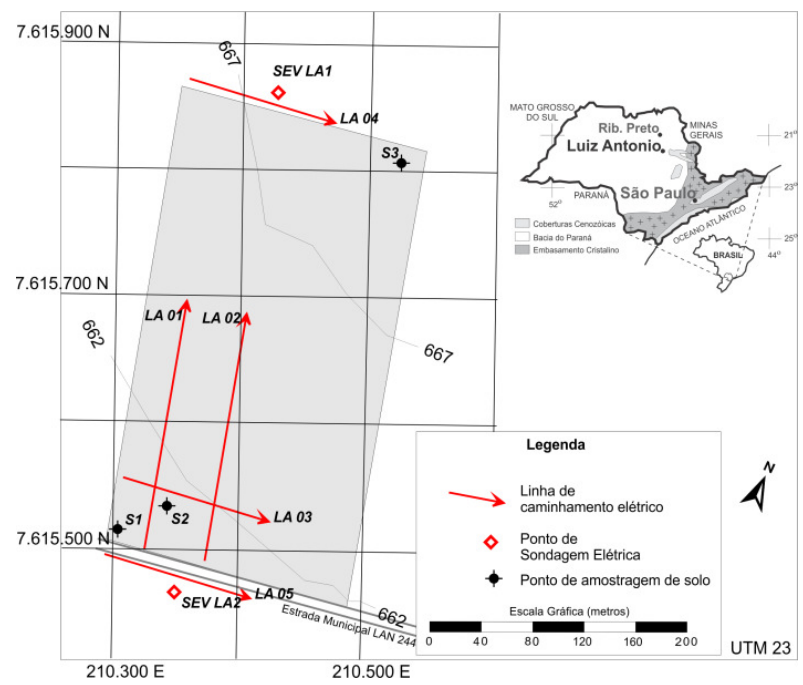

Figura 1 - Mapa do local e ensaios realizados

\section{Resultados}

Para as simulações com modelos 2D, na situação onde não há infiltração de chorume na base, a anomalia de baixa resistividade fica praticamente restrita a área da vala preenchida com resíduos, até 6 metros de profundidade. Pode-se observar, na Figura 2, que os limites laterais da vala são muito bem definidos e a anomalia de baixa resistividade fica muito próxima da base.

No caso com infiltração de chorume, os limites laterais da vala são bem definidos, mas a zona de baixa resistividade extrapola os limites da vala, indicando a influência do chorume no solo natural (Figura 3).

Para os ensaios de campo, as imagens elétricas foram interpretadas com base nos resultados das inversões nos modelos. Na Figura 4 é mostrada a seção obtida na vala 1 (LA 01), onde pode-se observar claramente os limites laterais das valas e que a anomalia de baixa resistividade extrapola a base da cava, indicando que ocorre contaminação no solo.

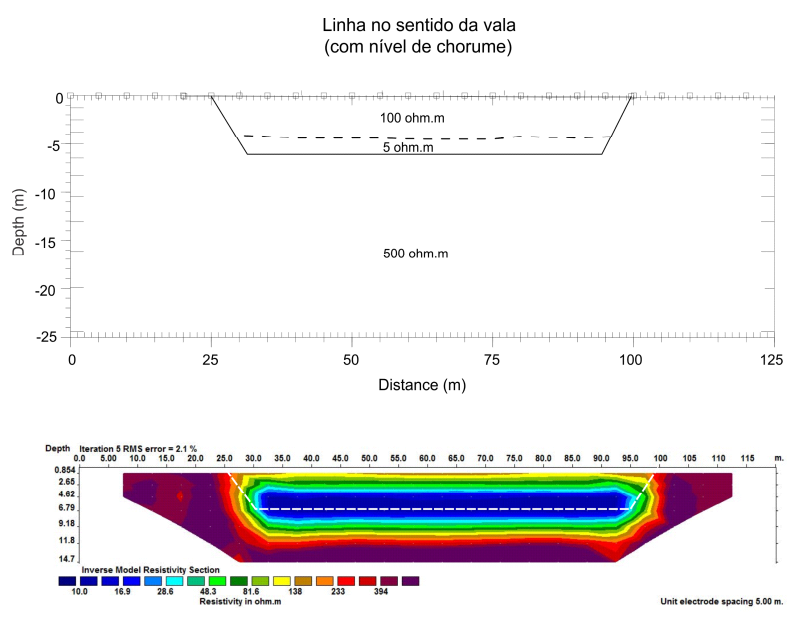

Figura 2 - Resultado da inversão para o modelo sem infiltração de chorume na base da vala.
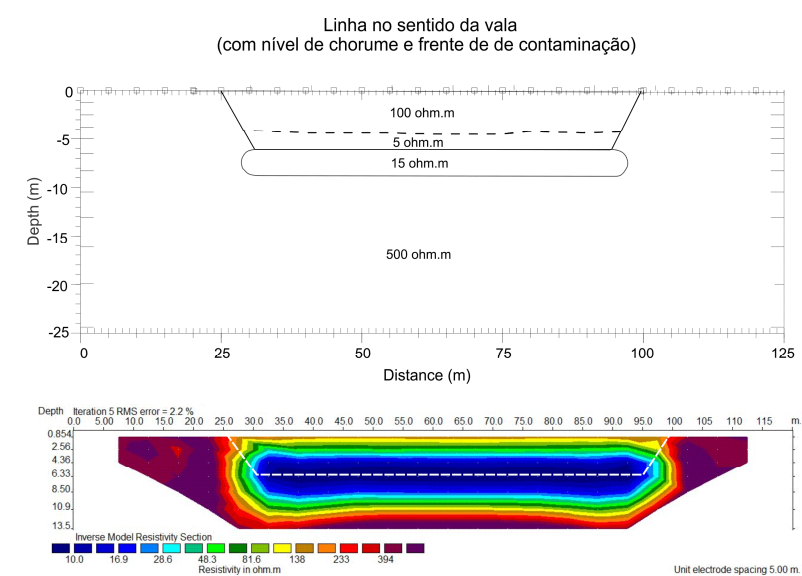

Figura 3 - Resultado da inversão para o modelo com infiltração de chorume no solo.

Na Figura 5 é apresentada a seção de resistividade obtida em ensaio perpendicular as três valas (LA 03). Pode-se observar que as três valas são claramente identificadas e que existe anomalia de baixa resistividade 
abaixo da base das valas, principalmente na vala do centro.

Para verificar se existia fluxo lateral de contaminantes, foi realizado um ensaio a jusante das valas (LA 05). Esse perfil, mostrado na Figura 6, fica a 10 metros do início da vala 1 , perpendicular a esta vala. Pode-se observar que não existe anomalia de baixa resistividade, sugerindo que possivelmente não ocorre migração da contaminação nesse sentido. Devido ao fato de os valores de resistividade serem mais elevados que nas seções com resíduos, não foi utilizada a mesma escala de cores. Em relação aos outros perfis a comparação não se deve ser visual, e sim deve-se observar os valores de resistividade.

Com base nos resultados geofísicos, foram retiradas amostras de solo em três posições: uma distante das valas (amostra S3), em área sem contaminação, e outras posicionadas próximas da vala 1 (amostras S1 e S2), onde teoricamente poderia haver contaminação (vide pontos de amostragem no mapa da Figura 1). Essas sondagens atingiram 24 e 26 m e não detectaram a zona saturada. Foram analisadas amostras de solo a cada 2 metros. Nessas análises foram encontradas concentrações maiores que o ponto de controle para os parâmetros sódio, cloreto, nitrogênio e nitrato. Porém as concentrações ficaram abaixo dos valores máximos permitidos pela legislação brasileira para áreas agrícolas (CETESB, 2005), onde se insere o aterro.

\section{Discussão e Conclusões}

Os aterros em valas vêm sendo cada vez mais utilizados no Brasil. Esse estudo mostrou que devido as valas não utilizarem sistema de impermeabilização na base, existe migração de contaminantes para o solo, como ficou caracterizado pelos ensaios geofísicos. Os dados de análise de solo, no entanto, mostraram contaminação abaixo dos limites permitidos, indicando que embora ocorra infiltração de contaminantes, as concentrações são minimizadas pelo efeito de atenuação natural do solo.

\section{Agradecimentos}

Ao CNPq (processo 303288/2013-2).

\section{Referências}

CASTILHOS JUNIOR, A. B. (Coord.). 2003. Resíduos sólidos urbanos: aterro sustentável para municípios de pequeno porte. Rio de Janeiro: ABES, RiMa, 288p.

CETESB - Companhia Ambiental do Estado de São Paulo. 2005. valores orientadores para solos e água no Estado de São Paulo. Decisão de Diretoria no 195-2005E, $4 p$.

INTERPEX LIMITED. 1997. RESIX IP2DI v3 - Resistivity and Induced Polarization Data Interpretation Software. User's Manual. INTERPEX Limited, Golden, Colorado, U.S.A., 280 p.

IWAI, C.K. 2012. Avaliação da qualidade das águas subterrâneas e do solo em áreas de disposição final de resíduos sólidos urbanos em municípios de pequeno porte: aterro sanitário em valas. Tese de Doutorado, Faculdade de Saúde Pública, USP, São Paulo-SP, 269 p.

LOKE, M.H. 2007. RES2DINV ver. 3.4 - 2D resistivity and IP inversion. Penang: M.H. Loke Software User's Manual.

Linha 01 - no sentido da vala

Depth Iteration 4 RMS error $=36.4 \%$

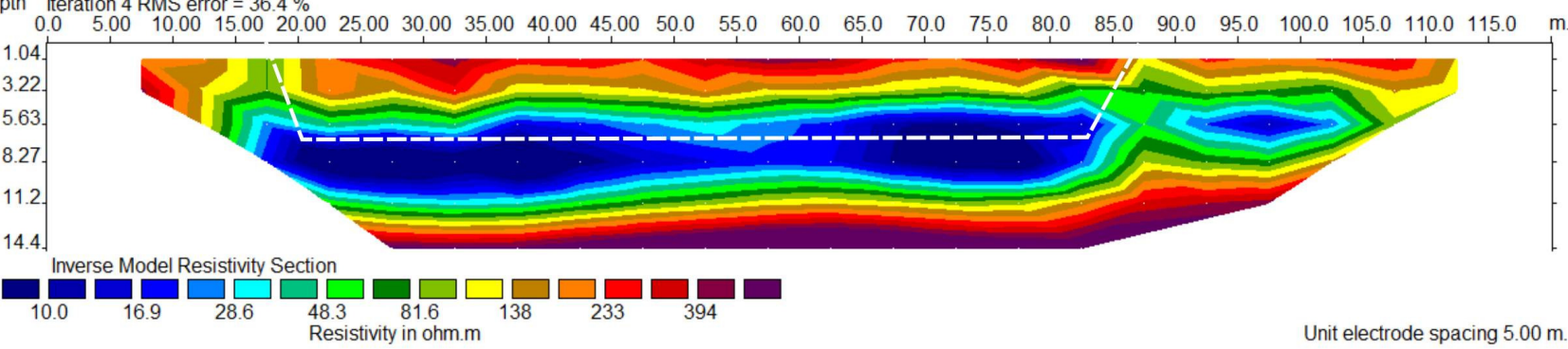

Figura 4 - Seção de resistividade da vala 1. 
Linha 03 - perpendicular a 3 valas

LA 03

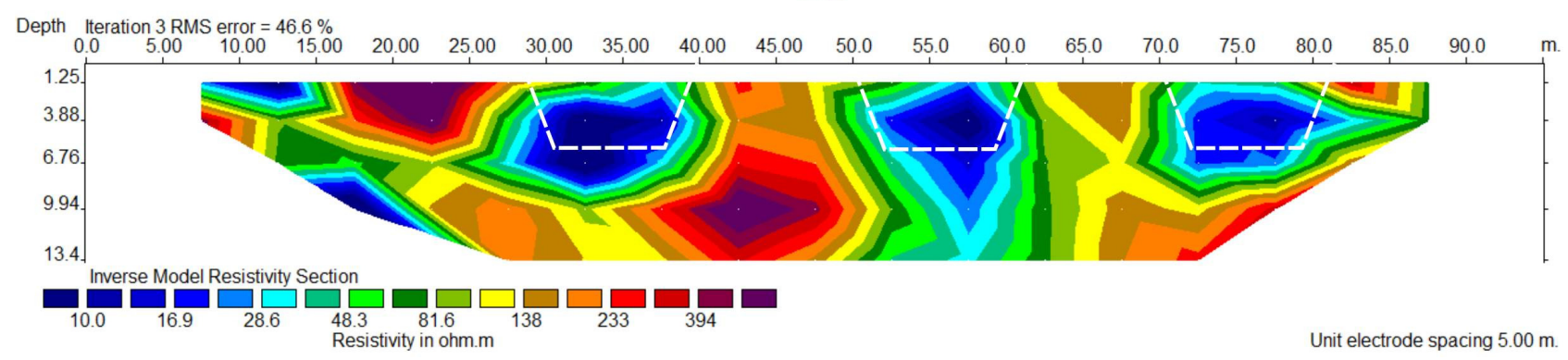

Figura 5 - Seção perpendicular a três valas.

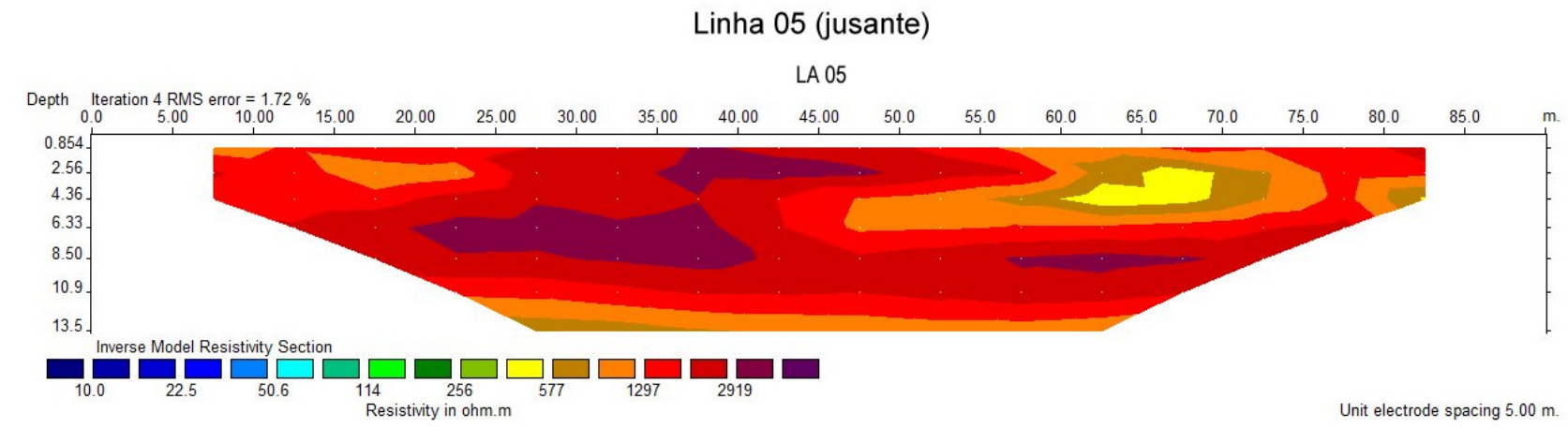

Figura 6 - Seção a jusante do aterro em valas. 